\title{
The Interplay of Metaphor and Iconicity: A Cognitive Approach to Poetic Texts*
}

\begin{abstract}
This essay attempts to clarify the interrelationship between the notions of metaphor and iconicity in the theory of cognitive metaphor, particularly in the model of 'blending' (Turner and Fauconnier 1995, in press, Fauconnier and Turner 1996, Turner 1996, 1998, among others). In cognitive and semiotic terms, 'icons' and 'metaphors' share that property of signification 'motivated' by similarity. Connecting things of similarity is one of the basic operations of the human mind. The treatment of metaphor and iconicity in an interrelated fashion will provide a more cohesive and integrated explanation of various linguistic phenomena. The list of such phenomena includes word formation, word order, grammaticalisation, semantic change, poetic discourse, signed languages and writing systems, as manifestations of the interplay between metaphor and iconicity. This study shows that poetic texts, in particular, serve as an optimal example in this exploration because in poetic discourse, the interplay of metaphor and iconicity is foregrounded rather than backgrounded as in everyday discourse (Jakobson and Waugh 1979).

This paper, therefore, aims to contribute in the following two issues. Firstly, theoretical clarification of the interplay of metaphor and iconicity will be given in cognitive terms. Particularly, with the model of blending, we can specify which part(s) of the

* This is a revised and enlarged version of my paper entitled as "Metaphor-Icon Link in Poetic Texts: A Cognitive Approach to Iconicity", appeared in the Journal of the University of the Air, No. 16, 1998, pp. 147-175. Previous versions of parts of this paper were also presented at various meetings, most notably at the 5th Congress of the International Association for Semiotic Studies held at University of California, Berkeley, in June 1994 (co-authored with Joanna Radwanska- Williams), and at the Annual Conference of Poetics and Linguistics Association held at Queen's University, Belfast, in April 1996. I would like to express my hearty gratitude to Hayley Davis, Don Freeman, Margaret Freeman, Joseph Goguen, Joanna Radwanska-Williams, Joan Turner, Mark Turner, and Valerie Wilkinson for their invaluable comments at various stages of this project.
\end{abstract}


metaphorical process - whether the input, generic, or blended spaces - relate(s) to the iconic mapping of form and meaning. Secondly, the analysis will demonstrate how the interplay of metaphor and iconicity is manifested in linguistic signs in general, and in poetic texts in particular. It will be claimed that there are two major types of manifestation: (i) that there are iconic moments in metaphor; and (ii) that a form acquires an iconic meaning via metaphor.

\section{Introduction}

Over the past decade, there has been a growing interest in metaphor and iconicity in the fields of cognitive and functional linguistics ${ }^{1}$. Those linguists who have begun to look at metaphor and iconicity share the basic assumption that the nature of language structure and use is not entirely arbitrary but motivated in many cases by the general cognitive processes of analogical reasoning. The American philosopher, Charles Sanders Peirce, influenced the pioneers in the mid-20th century linguistics, such as Jakobson (1971 [1966]) and Bolinger (1977), in their explorations of iconicity in linguistic signs. Although Peirce treated iconicity as embracing metaphor in his famous doctrine of the sign ${ }^{2}$, this close link of iconicity and metaphor has not fully been elaborated in the literature ${ }^{3}$. Even those current linguistic studies that have incorporated iconicity in the scope of their analysis have either discarded issues of metaphor from their studies (Haiman 1985a, 1985b, Waugh 1992, 1994, among others) or treated iconicity as a subordinate issue to metaphor (Lakoff and Johnson 1980, Lakoff and Turner 1989).

By contrast, this study attempts to clarify the interrelationship of metaphor and iconicity in the context of a cognitive theory of metaphor. The particular cognitive framework that we will use is the model of 'blending'4 proposed by

1 For the working definition of 'metaphor' and 'icon' to be employed in this paper, see Sections 2 and 3.

${ }^{2}$ Peirce divides iconic signs into three subtypes, images, diagrams, and metaphors, and gives the following definition: "Those which partake of simple qualities, or First Firstness, are images; those which represent the relations, mainly dyadic, or so regarded, of the parts of one thing by analogous relations in their own parts, are diagrams; those which represent the representative character of a representamen by representing a parallelism in somethiug else, are metaphors (Italics in the original)" (1955(1902]: 105). The in-text reference with different years of publication indicates that the year in brackets is a source or an original work and the year in parenthesis is an access volume according to which the citation is made.

${ }^{3}$ Danesi ( 1995) and Taub ( 1997) are exceptions. The former deals with the image content of metaphor as iconicity and reports a psycholinguistic experimental study. The latter is a detailed survey of an iconmetaphor link in American Sign Language.

4 'Blending' actually covers a wide range of linguistic and non-linguistic phenomena including "conceptual metaphor, metonymy, counterfactuals, conceptual change" (Turner and Fauconnier 1995: 
Turner and Fauconnier (Turner 1996, 1998, Turner and Fauconnier 1995, in press), which provides a more elaborated and sophisticated account of the mechanism of creativity in metaphor than the Lakoff-Johnson model (Lakoff and Johnson 1980). By introducing four items (two input spaces (a source and a target), a generic space (which preserves abstract shared properties of both inputs), and a blended space (in which new meanings are emergent)), the model of blending can specify which part(s) of the metaphorical process relate(s) to the interplay of form and meaning in the text, and thereby can clarify the complexity of systematic creation and interpretation of ambiguity with reference to the ways visual and auditory representation contribute in this process of meaning creation.

In cognitive and semiotic terms, icons and metaphors share a common property of signification, namely, that 'motivated' by similarity. Whether the items to be connected are concrete objects, formal structures, relational properties or abstract concepts, connecting things of similarity is one of the basic operations of the human mind. Iconicity deals with a mapping between form (structure) and meaning in various degrees of abstractness, from concrete attributive similarities between objects to abstract relational analogies between structures of form and meaning. On the other hand, metaphor is a mapping between two conceptual domains of meaning, a projection of a schematised pattern (system) from a less abstract source domain onto a more abstract target domain. The clarification of a metaphor-icon link will strengthen the cognitive approach so as to provide a more cohesive and integrated explanation of various linguistic phenomena, including word formation, word order, grammaticalisation, semantic change, poetic discourse, signed languages and writing systems, as manifestations of the metaphor-icon link. I believe, in particular, that poetic texts, like signed languages (Taub 1997) and logographic writing systems, are particularly suited for this exploration because in poetic discourse a metaphor-icon link is foregrounded rather than backgrounded as in ordinary spoken discourse (Jakobson and Waugh 1979).

This paper, therefore, contributes to the following two issues: (1) theoretical clarification - defining the interrelationship of metaphor and iconicity in the model of cognitive metaphor. In particular, the model of 'blending' proposed by Turner and Fauconnier offers an effective tool to analyse how iconicity relates to various parts of the metaphorical process; (2) demonstration - examining how a metaphor-icon link is manifested in the illustrative examples of poetic discourse.

183), "classiiication, the making of hypotheses, inference, and the origin and combining of grammatical constructions", (ibid., 186) "idioms,..., jokes, advertising, and other aspects of iinguistic and nonlinguistic behavior" (ioc. cit.). 


\section{A Glimpse of the Issue}

\subsection{Metaphor in Icon}

It is only recently that the word 'icon'5 has become readily understood as a loan word in Japanese. This is because of the persuasiveness of computer culture. When you actually manipulate the 'folders', 'documents' and 'wastebasket' on the 'desktop' of your computer screen, you can see the shape of the folders and open, move, close or even discard them into the wastebasket as you wish ${ }^{6}$. You can understand what the icons stand for even without instructions because the folders and documents on the screen resemble the objects that you already know in your office. The folder on the screen is an icon for a folder; the document for a document, the wastebasket for a wastebasket, the desktop (the term actually refers to the screen itself) for the surface of a desk. Icons resemble the objects they stand for in terms of their shape, form, appearance or structure. Icons are easy to understand because their resemblance to the objects is immediate and concrete.

A moment's reflection, however, makes us realise that the folder, document, wastebasket and desktop are very different from the objects that we actually have in our office. Folders in our office do not include other folders in them, while folders on the screen can, in theory, contain an unlimited number of other folders. In our office, we do not usually put a wastebasket on the top of our desk, but the desktop of the computer screen has a wastebasket on the same surface as the file-folders ${ }^{7}$.

The use of the words, folder and desktop, to signify these icons is metaphorical in a technical sense, because we are making connections between different things based on the certain similarities. The folders represented by icons on the screen as well as the folder objects in our office are containers of information used for the purpose of storage and classification. The desktop is a place where we work both on the screen and in the office. When we call the rectangular signs on the screen folders and documents, the names for the icons

5 In this essay, the term'icon' is used in a narrower semiotic sense as defined above than is usually employed in computer jargon in which it may refer to any visual symbols.

6 The computer examples mainly concern Macintosh screen display.

7 Incidentally, the wastebasket on the Macintosh screen is used not only for dumping the documents or applications, but it is also used for ejecting the floppy disks or compact disks from the drive. The latter function contradicts our conceptualisation of a wastebasket to the extent that the computer users often find it difficult or unnatural to follow this ejecting procedure of the disk. 
are a metaphorical extension of the original items which signify the referents (i.e., the folder object and the document object). Names such as folder, document and desktop, with their extended metaphorical meaning, cue the interpretation of the iconic signs. If we call these iconic signs by different names, say, 'box' or 'rectangle', it would be difficult to draw the connection, because the metaphorical extension is less obvious. In short, a metaphor reinforces or navigates the iconic meaning of the sign.

The folders, documents and wastebasket on the computer screen can be described as both icons and metaphors at the same time. They are icons because they look similar to the objects they represent. They are metaphors because, through metaphorical extension of the names given, certain properties of the concept of folder, document and wastebasket are cognitively mapped onto the signs on the screen, or onto the mathematical computation represented by those signs. Because of the visual resemblance of the folder and wastebasket icons with actual folders and wastebaskets, we notice their iconicity more readily than their metaphorical status. In other words, while iconicity is more dominant than metaphor in the computer screen example, both iconicity and metaphor are at work in the signification of highly iconic signs.

\subsection{Iconicity in Metaphor}

Metaphor and iconicity occur together at the level of metaphorical signification, too. When computer jargon became popular, we began to use it in talking about something else. For example, when we say, "I have too many files open in my mind, and my mind is jammed", we are referring to our mind as if it were a computer ${ }^{8}$. Here, we are not only using expressions from computer vocabulary, but we are also conceptualising our mind as if it were a computer ${ }^{9}$. So, we also say,
a. My system crashed.
b. He has a read-only memory.
c. You gave me a lot of input.
d. I have too much on my desktop.
e. She's in emulation mode.

Metaphorical expressions are illustrated in italics, and metaphorical concepts in uppercase letters.

This does not imply that there is not also the reverse process of conceptualisation, i.e., understanding computers in terms of the human mind - COMPUTER IS A MIND. We say, for example, "this computer has a large memory", "His computer has a mind of its own", and "My computer is stubborn." 
Metaphor allows us to understand a relatively abstract and unstructured subject matter (technically called a target domain) in terms of a more concrete and structured subject matter (a source domain). In our example, we use the terms designating computer processes as tools to represent the workings of our own minds. We know how to install, save and delete information in the computer because these are the terms that describe our practical experience with the computer. Therefore, it is natural to apply the pattern knowledge gained from the experience of using a computer to the invisible, complex functioning of our own brain. This is the experiential basis for metaphorical conceptualisation.

The same process that made computer icons of the files, desktops, and wastebaskets of the conventional office makes those same icons useful for conceptualising the functioning of the brain; we use items which are cognitively accessible as the source for metaphors. Metaphors may be imaged from visual, auditory, and other sensory experience. When we say, "I have too many files open in my mind", it is easy to evoke the image of a screen with many files open. And the image evoked in our mind is similar to the actual computer screen with many files open. In this way, we can say that the image content of metaphor, particularly of a source domain, is an iconic moment involved in metaphor. In Danesi's words ( 1995: 266), "the particular content of a metaphor can be said to constitute an interpretation of reality in terms of mental icons that literally allows us to see what is being talked about (italics in the original)".

Not only the image content but also the correspondence of the two items mediated by metaphor signal an iconic moment. As mentioned earlier, metaphor is a mapping from a source to a target. Each mapping consists of a fixed set of correspondences between entities in the two domains. In our example, some of the characteristics of computers are mapped onto what we know about the human mind. For example, files correspond with the storage of ideas, crash with no functioning, read-only memory with a lack of leamability, input with information, and emulation mode with imitating.

Technically speaking, this mapping is a projection of image-schemas from the source domain onto the target domain. Image-schemas are skeletal patterns or structures that recur in our sensory and motor experiences, perceptual interactions, and cognitive operations (cf. Johnson 1987). For example, when we say, "I have too many files open in my mind", the image-schema of excess in the source ('too many opened files') and in the target ('too many ideas') are aligned. Note that there is an iconic moment in this alignment of imageschemas. The image of too many files corresponds to the image of too many ideas diagrammatically. In other words, they resemble each other in terms of the image-schemas of excess. There is a structural analogy between the two image-schemas.

While iconicity was more dominant in the computer screen example, metaphor is more dominant than iconicity in the signification process of MIND 
IS A COMPUTER, because the projection of the COMPUTER domain onto the HUMAN MIND domain is more conceptual than perceptual (visual, auditory or sensory). Nonetheless, the experiential motor-sensory image base and schematic parallel structure are iconic moments in the metaphorical signification (for further technical elaboration, see next section).

In what follows, I would like to demonstrate that in linguistic signs (Section 3), and particularly in poetic texts (Section 4), a close link between metaphor and icon is manifest in the two ways outlined above: (1) that there are iconic (both imagic ${ }^{10}$ and diagrammatic) moments in metaphor; and (2) that a form (structure) acquires an iconic (particularly, diagrammatic) meaning via metaphor. I would also like to show that the model of 'blending' proposed by Turner and Fauconnier (Turner 1996, 1998, Turner and Fauconnier $1995,1999)$ provides an effective instrument to clarify the complexity of the metaphoricon link.

\section{Theoretical Implications of Metaphor-Icon Link}

\subsection{Iconicity and Metaphor Defined}

In cognitive terms, iconicity (i.e., images and diagrams in Peircean terminology) deals with a mapping between form (structure) and meaning (cf Lakoff and Turner 1989) in various degrees of abstraction, from concrete attributive resemblance to abstract relational analogy. Metaphor, on the other hand, is a mapping between two conceptual spaces of meaning, a projection of a schematised pattern (system) from a less abstract source space onto a more abstract target space (cf. Lakoff and Johnson 1980, Lakoff 1987, 1993, Turner 1996).

It is often the case that the basis of similarity in the icons is derived from visual, auditory and other formal traits of the object that they stand for, and that the iconic signs are often the visual, auditory or formal representations themselves. Metaphors, on the other hand, do not necessarily have such traits. Rather, they manifest themselves as a heuristic device to mediate dissimilar concepts by means of the similarity they yield. As Anderson (1984: 459) correctly points out, "a metaphor, like an image or an analogy, is what it represents - but not because of an antecedent identity or similarity, not as a reminiscence, but in virtue of a similarity which it creates". Indeed, in icons, the similarity relationship between the sign and the object is taken to be pre-existent. For example, we assume that there is a similarity between the folder icon and the folder object even if we

10 The tetm 'imagic' is used to refer to Peircean notion of 'image' as a subtype of iconicity (For the definition of Peircean notion of 'image', see Footnote 2). 
have no prior experience with the computers. In contrast, a metaphor connects two entities, say a mind and a computer, which are apriori dissimilar. The connecting act via a metaphor establishes the similarity between the two dissimilar entities, and thus creates a new meaning or interpretation.

\subsection{Iconic Moments in Metaphor}

Although cognitive linguistics offers a clearer definition for metaphor and iconicity, it is not satisfactory that they treat metaphor and iconicity as somewhat isolated manifestations from each other. Because metaphor and iconicity are similar cognitive operations motivated by analogical reasoning, they would be best captured in their interplay rather than isolation as Peirce correctly suggested but failed to develop.

It will be claimed that the model of blending developed by Turner and Fauconnier (Turner 1996, 1998, Turner and Fauconnier 1995, in press, among others) offers a promising theoretical basis and an effective methodological contribution to explicating the interrelationship of metaphor and iconicity (i.e., Peircean 'image' and 'diagram') and analysing their actual manifestations in language. Turner and Fauconnier (1995: 184) propose a model of "conceptual projection across four or more (many) mental spaces rather than two domains", to explain a wide range of phenomena including "conceptual metaphor, metonymy, counterfactuals, conceptual change" (ibid., 183), "classification, the making of hypotheses, inference, and the origin and combining of grammatical constructions", (ibid., 186) "idioms ........... jokes, advertising, and other aspects of linguistic and nonlinguistic behaviour" (loc. cit.).

The basic claims of the cognitive account of metaphor, developed by Lakoff, Johnson and Turner (Lakoff and Johnson 1980, Lakoff 1987, Lakoff and Turner 1989, Lakoff 1993), and elaborated as a more general model of 'blending' by Turner and Fauconnier can be summarised as follows (see Figure 1):

(1) Metaphor is a cognitive process in which one set of concepts (a target) is understood in terms of another (a source). According to the model of blending, metaphor is a conceptual integration of four mental spaces ${ }^{11}$. Mental spaces are small conceptual arrays constructed for local purposes of understanding. When a conceptual projection occurs, two input mental spaces (source and target in a metaphor) are created. These input spaces have relevant information from the

11 Turner and Fauconnier use the term 'mental space' in contrast to the term 'conceptual domain', employed by Lakoff, Johnson, and other cognitivists. Mental spaces are small conceptual arrays put together for local purposes of action and understanding, while conceptual domain is a vast structural array that could not be made active in thinking (cf. Turner 1996). 
respective domains, as well as additional structure from culture, context, point of view and other background information.

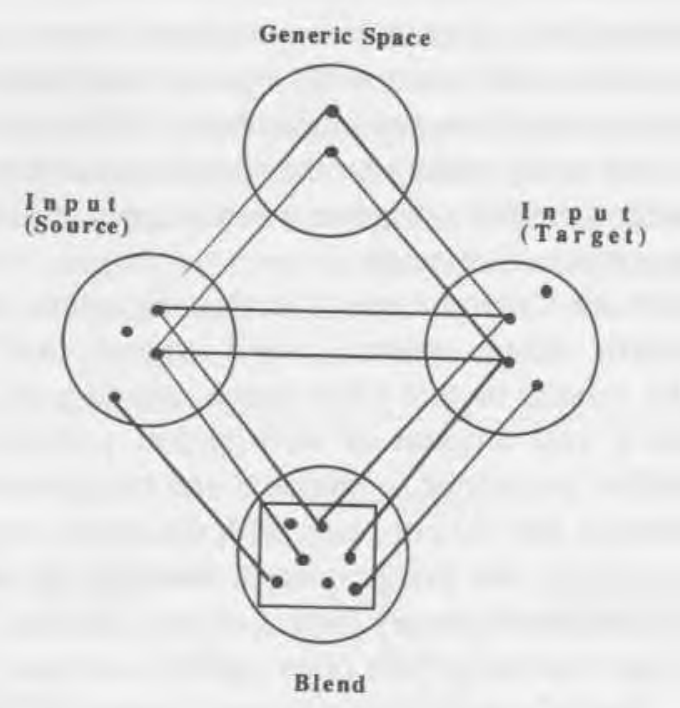

Figure 1. The Model of Blending ${ }^{12}$

(2) There are two kinds of middle mental space in addition to the input spaces. These middle spaces are: (i) a generic space that applies to both input spaces; and (ii) a blended space that is a rich space integrating the generic structure, structures from each input space and background information. Often the blended space has an emergent structure of its own.

(3) Each mental space has an image-schematic structure that is consistent and preserved through conceptual projection of generic and input spaces. The image-schemas are skeletal patterns in our sensory and motor experience, such as a container, a motion along a path, part and whole, centre and periphery, symmetry and so forth.

(4) The blended space develops inferences, arguments, ideas and emotions, which can modify the initial input spaces and change our views of the knowledge used to build those input spaces (cf. Turner 1996: 83).

Let us take the example, "I have too many files open in my mind", and recapitulate the main points about iconic moments in metaphor according to the model of blending. As we have seen, the conceptual metaphor, MIND IS A

- Figure 1 is based on the graphic representation of blending provided in the website for blending http://www.wam.umd.edu/ mturn/ W W W/blending, html/). 
COMPUTER, allows us to understand an abstract entity, a human mind, in terms of a concrete entity, a computer. The cross-space mapping between the inputs constitutes the content of the generic space. In our example, the image-schemas of objects resembling fdes, an excessive amount of them, a machine and its movement in the source input («too many opened files') are aligned with the image-schemas of abstract objects and manipulation of the mass of these objects in the target input ('too many ideas') by the generic space which has the highly abstract, skeletal image-schematic structure taken to apply to both the input spaces (e.g., a frame of an excess of objects).

Notice that there are iconic moments in this alignment of image-schemas. The choice of the term, 'image-schema', itself suggests that both 'image' and 'diagram' are to be related to this cross-space mapping of metaphor. In the input spaces, from a vast amount of information provided by our bodily experiences, interactive perception, contextual and background knowledge, we have an array of images that do not clash with the entire cognitive process of metaphor. In our example, the image content includes visual (or interactive) images of an action of opening many files, a screen showing many files open, a dialogue box saying 'too many files open', and/or a screen frozen due to too many files open. These are mimetic mental representations of sensory perceptions, and constitute imagic iconicity. At the same time, a mental space develops a structure by selecting and schematising the images, namely, an image-schematic structure, which has a diagrammatic representation of the image content of mental space (e.g., an image-scheme of a blocked action due to an excessive amount of files). A similar process might occur in the target input space to a less concrete degree. For example, the evoked images for 'too many ideas' may be more abstract than what happens in the source, and so is its schematisation. Therefore, there are two types of iconic mappings in the input spaces: an attributive imagic mapping between the sensory perception and the image content, and an analogical diagrammatic mapping between the image content and the schematised images.

Conceptual and image projections do not only occur in input spaces, but they also include a generic space and a blended space. There is a relationship of similarity between the generic space and the input spaces, because the generic space has an imageschematic structure shared with the two inputs. This shared image-schematic structure is skeletal and abstract. In the metaphor, "I have too many files open in my mind", the generic structure can be an image schema of a purposed action or a progress which is blocked with a difficulty. As the image- schematic structure is preserved, the two input spaces are structurally analogous. The analogy supported by the generic space can be described as diagrammatic because it is a structure-preserving schematic correspondence between the source and the generic space, and between the target and the generic space. In other 
words, diagrammatic iconicity is at work in the analogy between the corresponding imageschematic structures of the generic space and the input spaces.

This metaphor gets its full interpretation and understanding as a conceptual integration in the blended space, in which we have a conceptual mapping of partial structures from both inputs and the generic space, and which develops an emergent structure of its own, for example, disorder, a lack of proper motion, a stoppage, as a result of excessive movements. Figure 2 illustrates imagic and diagrammatic iconic mapping inherent in the conceptual mapping and integration of metaphor.

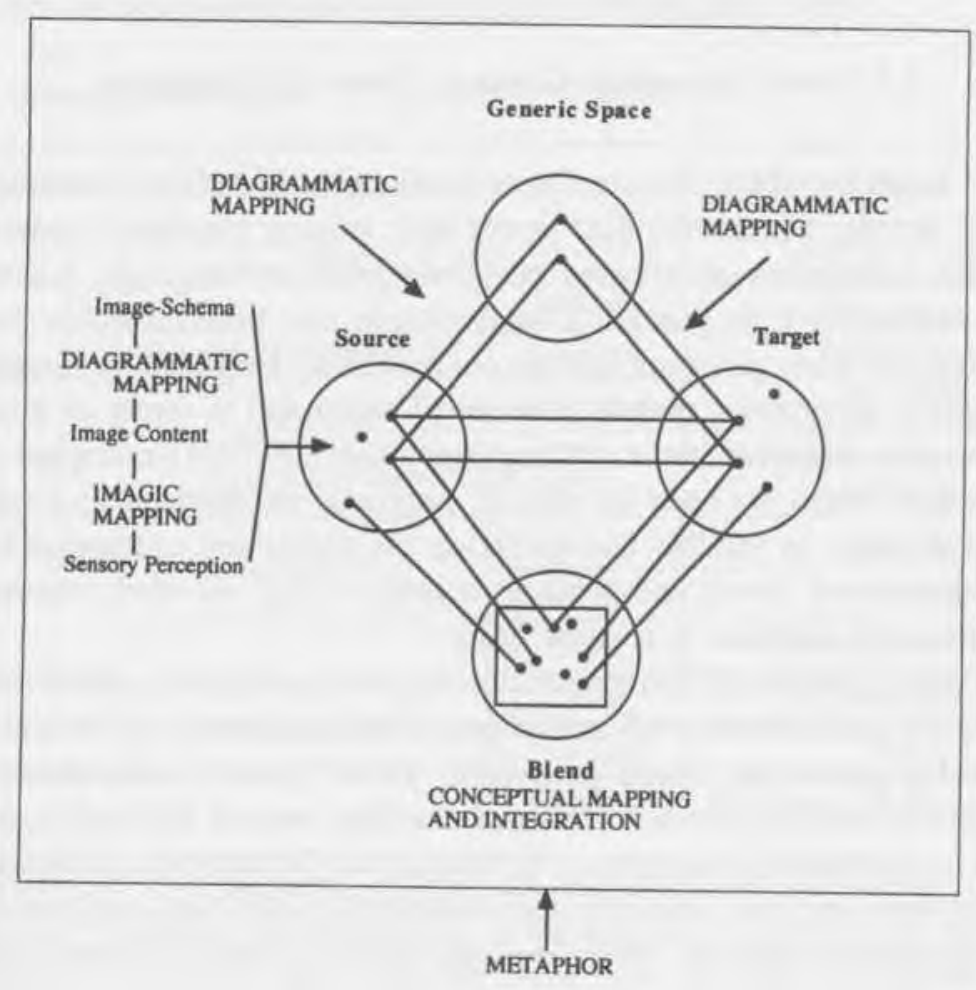

Figure 2. Metaphor-Icon Link in the Model of Blending

Needless to say, it is metaphor rather than iconicity that prevails in this particular example of "I have too many files open in my mind." For only the very abstract conceptual (theory-building) level seems to involve iconic moments: imagic and diagrammatic iconicity in the evoking of images and the schematisation of images in the input mental spaces, and diagrammatic iconicity 
in the correspondence or counterpart projection of image-schematic structures between the generic space and input spaces.

The discussion above has illustrated that the model of blending lends itself to understanding semiotic implications of imagic and diagrammatic iconicity in the cognitive process of metaphor. When we say that metaphor has iconic moments, it means that there are some traces of iconic mapping in general between a fairly abstract form and a concept. No visible figure mirrors the concept in the linguistic representation of this particular example of a conventional metaphor. This does not mean that language structure and use are deprived of iconicity. Until linguistic iconicity is delineated, however, it will not become visible, because it is not foregrounded.

\subsection{Iconic Meanings Given to Form by Metaphor}

One of the ways by which we can detect iconicity in linguistic resources (such as sounds, words, sentences, discourses and writing systems) comes from conventional metaphors relating to our conception of language. Lakoff and Johnson (1980: 126-138) provide a basic insight into how metaphor can give meaning to form. They point out that we conceptualise language by orientational and ontological metaphors, that is, in terms of space and in terms of objects.

A pervasive conceptualisation of language is the CONDUIT metaphor (Reddy 1979) in which ideas are seen as objects, linguistic expressions as containers, and communication as sending and receiving the containers containing ideas as objects. Because we speak and write in a linear order, we also conceptualise language in terms of space in a linear order.

There are a handful of conventional conceptual metaphors which elaborate the ontological and orientational metaphors of language, and which function as a useful tool to give iconic meanings to form. Table 1 gives a non-exhaustive list of examples of such conventional metaphors. For ease of discussion, we will call these conventional metaphors Grammatical Metaphors, because these metaphors, more or less, concern the relationship of form and meaning in grammatical conventions (e.g., phonology, morphology, word formation, and word order).

Because we conceptualise expressions as containers and meanings as contents, we assume that the bigger containers have the larger contents. So, MORE FORM IS MORE MEANING. For example, prolongation, repetition, iteration, and reduplication of linguistic forms such as a sound, a syllable, and a word tend to stand for more of the content. The SAMENESS of FORM stands for the SAMENESS of CONTENT, the DIFFERENCE of FORM, the DIFFERENCE of CONTENT. For example, the use of the same (similar) sound signifies the same 
(or equivalent) meaning in English morphology, an [s] for the plural, a [non] for the negative prefix and so forth. LOCATION of FORM also gives iconic meanings. In general orientational experiences, we put important things in the centre. For example, there tends to be a building or a monument of importance (a castle, a church or a tower) at the centre of a city, a village or a campus. In English, for instance, when a word is embellished with inflections and affixes, they are peripheral. The stem, which expresses the core meaning, stays in the central position. It is rare that the central shape of a word is altered. Not only the location of the form, but also the sequential order of the form can mirror the space, time and causal sequence of the content. In the standard representation of temporal events, for example, it is more common to state things along the occurrence in time, from past to the present rather than reverse.

Table 1. Grammatical Metaphors

\begin{tabular}{|c|c|c|c|}
\hline Metaphor & Source & & Target \\
\hline \multirow{5}{*}{ Ontological } & \multicolumn{2}{|c|}{ Quantity of form } & Quantity of content \\
\hline & \multirow{3}{*}{ Identity or difference of } & Material & \multirow{3}{*}{$\begin{array}{l}\text { Identity or } \\
\text { difference } \\
\text { of content }\end{array}$} \\
\hline & & Location & \\
\hline & & Sequence & \\
\hline & \multicolumn{2}{|c|}{ Symmetry/asymmetry of form } & Symmetry/asymmetry of content \\
\hline \multirow{6}{*}{ Orientational } & \multirow{2}{*}{ Location of form } & Near & Strenght \\
\hline & & Centre & Importance \\
\hline & \multirow{4}{*}{ Sequence of form } & Linear & Sequence of time \\
\hline & & Linear & Cause/Effect \\
\hline & & First/Last & Value \\
\hline & & First/Last & Up/Down, Left/Right, Near/Far \\
\hline
\end{tabular}

Halliday (1994) has also noticed the diagrammatic correlation (which he calls 'iconic') between the expressions in the discourse grammar and the contents expressed. According to him, there are three types of such correlation:

(1) There is a movement from a given Theme (background) to a rhematic New (foreground); this movement in time construes iconically the flow of information.

(2) New semiotic entities are created by ... nominal packages, ...; the nominal expression in the grammar construes iconically an objectified entity in the real world.

(3) The combination of (1) and (2) construes iconically the total reality,... a reality consisting of semiotic entities in a periodic flow of information (1994:143). 
Halliday's notion of 'packages' and 'movement' is similar to the grammatical metaphors discussed above, namely, LINGUISTIC EXPRESSIONS ARE CONTAINERS and LINEAR SEQUENCE IS CHRONOLOGICAL OR CAUSAL ORDER; but, it goes further to point out that the nominal expressions are the prototypical construal of EXPRESSIONS as PACKAGES.

As a diagram refers to its object by virtue of similarity between the relationship among the parts of the diagram and the relationship among the parts of the object, the structure of linguistic representation resembles the structure of the content that it conveys. As in Caesar's "veni, vidi, vici" (I came, I saw, I conquered) (cf. Jakobson 1965: 350), the syntagmatic order of mention in speech corresponds to the chronological or causal order in which the event occurs. Paradigmatically, word affinity relations such as morphemes (e.g., 'acceptable",readable' 'replaceable' - sharing 'able' in form and "being CAPABLE of doing” in meaning), phonesthemes (e.g., 'gleam', 'glance', 'glare', 'glitter', etc. sharing initial $/ \mathrm{gl} /$ in form and "connection to vision" in meaning) and so forth, suggest that sameness in form signals sameness in meaning; difference in form signals difference in meaning. Diagrammatic icons are, in this sense, analogous to their objects in structure and/or in relation.

Semiotically speaking, these two examples illustrate two broad possibilities in which diagrammatic iconicity is manifested in grammar, and thereby receives interpretation as such by the presence of ontological and orientational metaphors explained above. We will call the two types of iconic form 'structural diagram' and 'relational diagram', which roughly follow Haiman's classification of diagrammatic iconicity into 'motivation' and 'isomorphism' (cf. Haiman 1985a, 1985b) ${ }^{13}$. 'Structural diagrams' display a correspondence between structure of form and structure of content, whereas 'relational diagrams' show a tendency to associate sameness in form with sameness in content; difference in form with difference in content. In an extreme case, this tendency is expressed as the principle of "one meaning, one form" (cf. Bolinger 1977). We can see relational diagrams as a special case of structural diagrams, as they presuppose the working of structural analogy. The difference between structural diagrams and relational diagrams seems to be that the former is a structural analogy whereas the latter is

\footnotetext{
${ }^{13}$ The terminology that I suggest here represents the nature of the two types of diagrammaticality more clearly by avoiding the confusions caused by different interpretations of different researchers for the two terms employed by Haiman, who defines 'motivation' as "ways in which the linguistic form is a diagram of conceptual structure, and homologous with it" (Haiman 1985b: 2) and 'isomorphism' as "the tendency to associate a single invariant meaning with each single invariant form" (Haiman i985b: 4). At the same time, the present classification secures the term 'motivation' for a more general use in which it signifies the 'non-arbitrary' relationship behveen form and meaning. Ohori ( 1987) offers an insightful critique of Haiman's classification of iconicity.
} 
a relational analogy. Structural diagrams tend to deal with a correspondence between the structure of linguistic form and the structure of conceptualisation; relational diagrams with a correspondence between the relation in linguistic form and the relation in linguistic meaning. Figure 3 is a graphical presentation of the two principles in question:

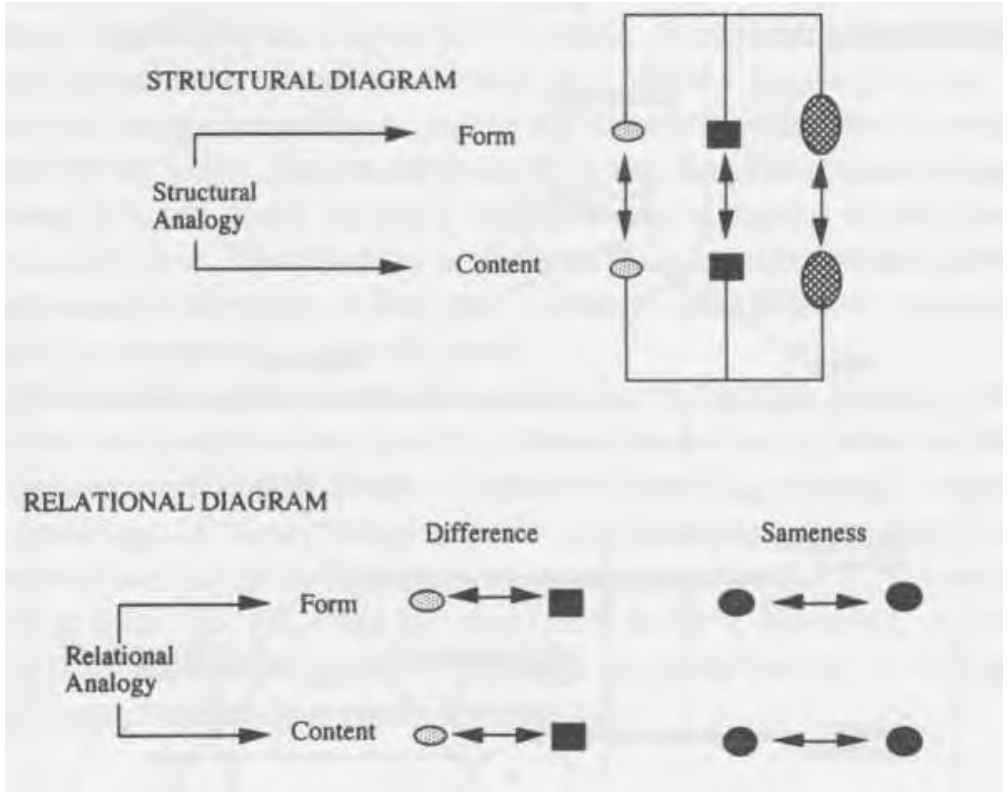

Figure 3. Structural and Relational Diagrams

Both auditory and visual forms can receive an iconic meaning from the grammatical metaphors, and function as structural or relational diagrams. The relationship of form and meaning in grammatical metaphorical mapping is diagrammatic, because what is preserved is an analogical relationship mediated indirectly by grammatical metaphors. This contrasts with a direct attributive connection such as pure imagic iconicity between the linguistic form and meaning, e.g., a case of onomatopoeia and visual language such as logographs (for more examples and discussion on grammatical metaphors and diagrammatic manifestations, see Jakobson 1970, Bolinger 1977, Haiman 1985a, 1985b, Waugh 1992, 1994, Hiraga 1994, among others).

To conclude the section, we have discussed that there are two types of metaphor-icon link in language: iconicity in metaphor and metaphor in icon. Iconicity in metaphor concerns the imagic and diagrammatic representation in the creation of meaning in metaphor. This is most prototypically illustrated in the notion of image-schematic structures crucial in the cognitive account for 
metaphor. Metaphor in icon also relates to imagic and diagrammatic aspects of the linguistic form. Conventional metaphors which conceptualise our everyday experiences and reality also conceptualise our understanding of language structure and use. These metaphors navigate the way we interpret the forms of linguist:; expressions.

The relationships of these two types of metaphor-icon link may be graphical/ represented by Figure 4:

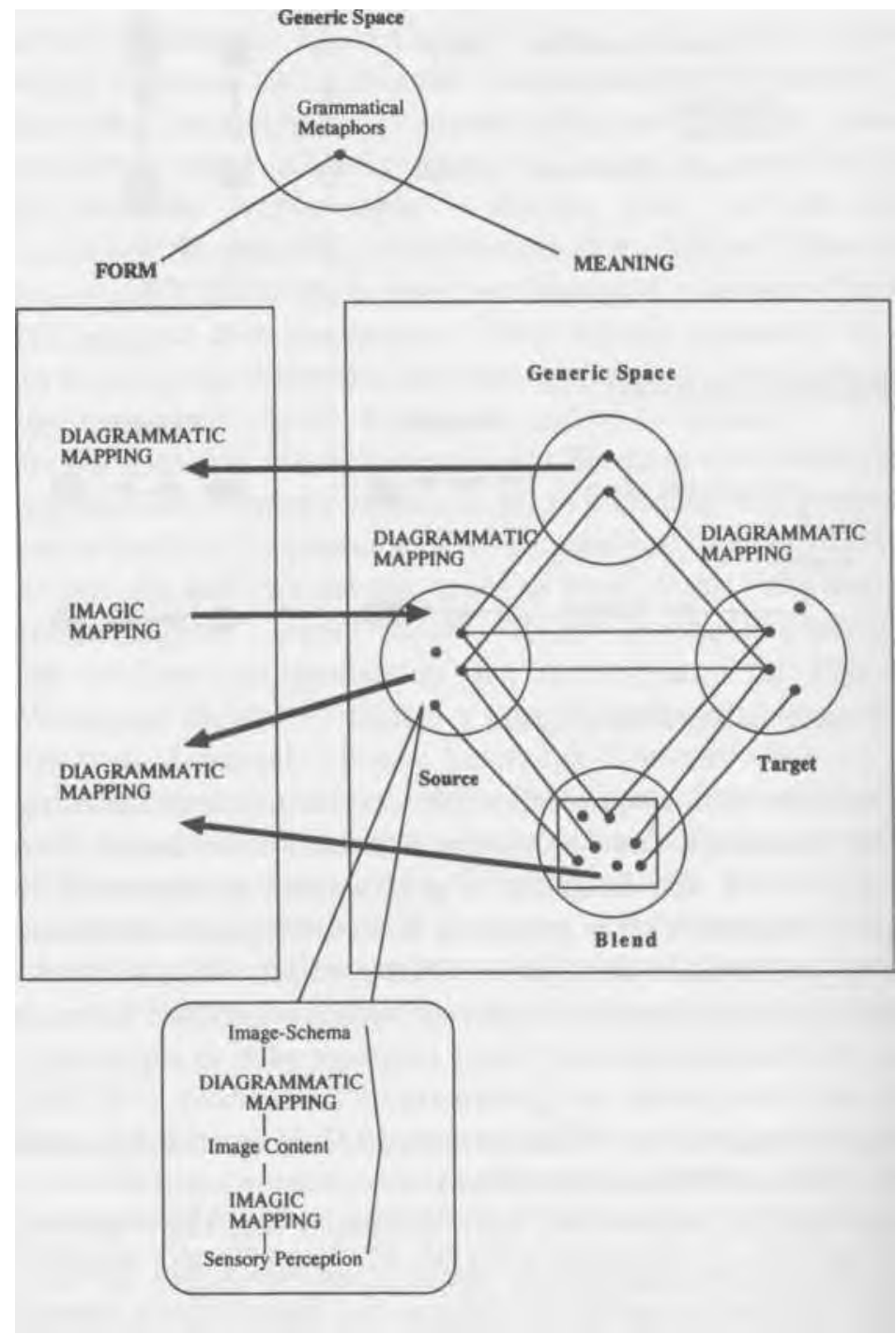

Figure 4. Metaphor-Icon Link in Language 
In the box of 'meaning', the metaphorical process is illustrated according to the model of blending. There are four mental spaces. Imagic and diagrammatic iconicity relate to (1) inside structure of input spaces in which sensory perception is projected onto the image content by imagic mapping, and then onto the image schema by diagrammatic mapping; and (2) the relationship of inputs to the generic spaces in which the diagrammatic mapping projects one space onto another. The box of 'form' represents the linguistic resources. When the form mirrors the meaning as in the case of onomatopoeia and visible language (e.g., some logographs), the imagic mapping occurs in the direction from form to meaning, as illustrated by an arrow. On the other hand, when the grammatical metaphors give meaning to form, there occurs a diagrammatic mapping in the direction from meaning to form illustrated by an arrow. The general structure preserved by this diagrammatic mapping of form and meaning constitutes the generic space in which the grammatical metaphors reside.

The effectiveness of the model of blending shows up here. For it is with this model that we can specify which part(s) of the metaphorical process - whether the input, generic, or blended spaces - relate(s) to the diagrammatic mapping of form and meaning. In theory there are four possibilities: a mapping (1) from generic space onto form; (2) from input source space to form; (3) from input target space to form; and (4) from blended space to form. However, in practice, the case (3) is unlikely because the target space in metaphor, by its own nature, is where the mapping finalises rather than initiates.

\section{Case Studies of Poetic Texts}

I have demonstrated that a framework of cognitive linguistics can provide a tool to analyse the intimate connection between form and meaning that iconicity requires, particularly with reference to an interrelated manifestation of metaphor and iconicity. The rest of this paper develops the idea that poetic texts foreground the link between metaphor and iconicity.

Even though it can be said that the metaphor-icon link is more overt than covert in poetic discourse as opposed to the situation in everyday discourse, mere are a variety of degrees and combinations with which metaphor and iconicity manifest themselves. Some texts, though smaller in number, display pure iconicity in which the visual or auditory form itself mirrors the meaning. It is often the case that such poems were composed with the conscious intention of being interpreted that way. Actually, most texts show iconicity more subtly through metaphors. Namely, metaphors are more predominantly produced and apprehended in most texts, and it is such metaphors which navigate the iconic interpretations of the textual structure. The metaphorical reading reinforces certain 
iconic interpretations prevailing in the textual form such as syntactic structures, phonological patterns, the parallelism of certain lexical items, or the choice of graphic characters, letters and layouts in writing.

As a prototypical illustration of the complexity of manifestations of the metaphoricon link, I would like to present an analysis of two short English. These poems display both local and global metaphors. Local metaphors are placed in various parts of the poem. They are based on either conceptual mappings (in which structured image-schematic concepts are mapped from one domain onto another, such as actions onto events, and a journey onto life [involving diagrammatic iconicity]), image mappings (in which locally evoked images are mapped from one onto another, e.g., the colour of objects mapped onto feelings [involving imagic iconicity]), or a combination of both. The local metaphors may or may not contribute to the formation of a global conceptual metaphor, which is a metaphorical reading of the whole text, i.e., the poem as metaphor.

The poems analysed below differ in the degree to which metaphor and iconicity are manifested in combination. The poems analysed below differ in the degree to which metaphor and iconicity are manifested in combination. The first one is an example of English pattern poetry, which displays an overt imagic iconicity. The second example is a covert manifestation of diagrammatic patterns in a single poetic text where diagrammatic iconicity is achieved through the choice of lexical items and grammatical parallelism. The analysis will demonstrate that in both examples, the metaphor-icon link is at work strongly in the creation and the interpretation of meaning.

In addition, the model of blending will be adduced as a means of clarifying the dynamic mechanism of the metaphor-icon link, because it allows us to see which part of the metaphorical process relates to which type of iconic mapping in the poetic text.

\section{1. "Easter Wings"}

Text as Icon

"Easter Wings" by George Herbert (1880 [1633]: 34-35) is one of the best-known examples of pattern poetry in the English language ${ }^{14}$. The poem is presented as

\footnotetext{
${ }^{14}$ A number of critical studies have been devoted to philological and rhetorical aspects of this poem. According to Westerwell ( 1984: 56), the most important works include Tuve 1952, Summers 1954, Walker 1962, Bennet 1963, and Higgins 1977. Of course, all of these studies have taken up the close link between form and meaning of the poem; but, none has a mention of this link as a case of iconicity.
} 
a silhouette of wings. The visual image mirrors the theme of the poem, which is concisely stated in its title, "Easter Wings". This is a typical example of imagic iconicity, as the relatianship of form and meaning is immediate and mimetic. The very shape of the poem - the rising wings of two birds - exhibits the content of the poem in which a human being relates to the actions of a bird (specifically as a lark).

\section{Example 1}

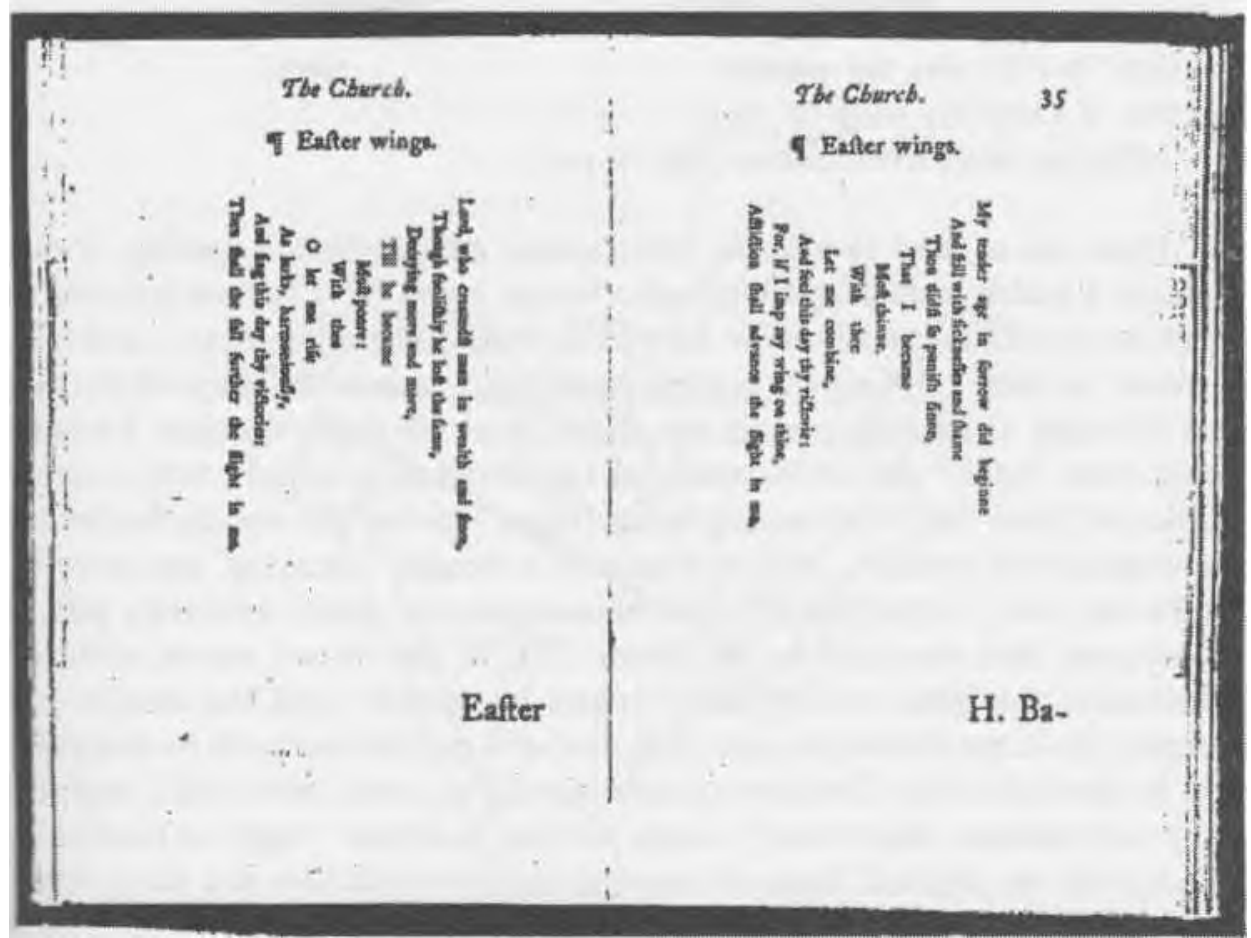

N.B. The following 'prosaic' presentation of the poem is provided only for the clarification of the content of this graphic representation.

Lord, who createdst man in wealth and store,

Though foolishly he lost the same,

Decaying more and more,

Till he became

Most poore:

With thee $\mathrm{O}$ let me rise As

larks, harmoniously, 
And sing this day thy victories:

Then shall the fall further the flight in me.

My tender age in sorrow did beginne:

And stiff with sicknesses and shame

Thou didst so punish sinne,

That I became

Most thinne.

With thee

Let me combine

And feel this day thy victorie:

For, if I imp my wing on thine,

Affliction shall advance the flight in me.

There are at least two major input spaces created by the reading of this poem as a global metaphor: a bird and a human being. This is done not only in linguistic expressions such as 'let me rise as larks', 'the flight in me', and 'imp my wing on thine', but also in graphic expressions such as the shape of the two sets of wings, and their layout on two facing pages. In the first stanza, a human being (both 'Adam' and all humanity) is (re)presented as a bird which is about to rise on Easter Day. God created Adam («man') giving him weaith, but he fell and forfeited his paradise. Man's abundance is steadily 'decaying' into poverty. God's only son, Christ ('thee'), enables man to 'rise' again spiritually just as Christ rose from the dead on the Easter Day. In the second stanza, with the inheritance of original sin, humanity begins in 'sorrow', and also decays into sickness. As in the first stanza, it is 'with thee' that provides an uplift for humanity and for the individual. The narrator sees himself as a bird which will 'imp' his wing with feathers from Christ's wings so as to make the 'flight' to heaven. In effect, both the physical flight (or strength to go on with life) and the spiritual uplift are implicated in the poem.

As illustrated in Figure 5, a bird is both the input source space for a global metaphorical mapping (onto a human being) and the target space for an imagic iconic mapping (from the visual source space of the wings of a bird).

The metaphorical mapping of a bird onto a human being is represented by the four mental spaces on the right-hand side of Figure 5.

In the source input space, we have an image-schema of a bird - a lark with wings, singing, flying, and the movement (expansion and contraction) of the wings. In the target input space, we have an image-schema of a human being - Adam ('man'), a narrator (human being in general), sin and retribution. In the blended space, a fused image-schema of a bird and a human being receives a dynamic structure from cultural background of Christianity. Adam's original 
sin is related to the punishment, mortality and death of human beings. Man's wealth is shrinking and decaying into poverty. The soul is also in decline. Then, Christ (as represented by 'thee') enables man to rise again spiritually. The victories of Christ on Easter day are celebrated by the song of a lark. The movement of wings, i.e., expansion and contraction, is mapped onto the process of decay and salvation of human beings.

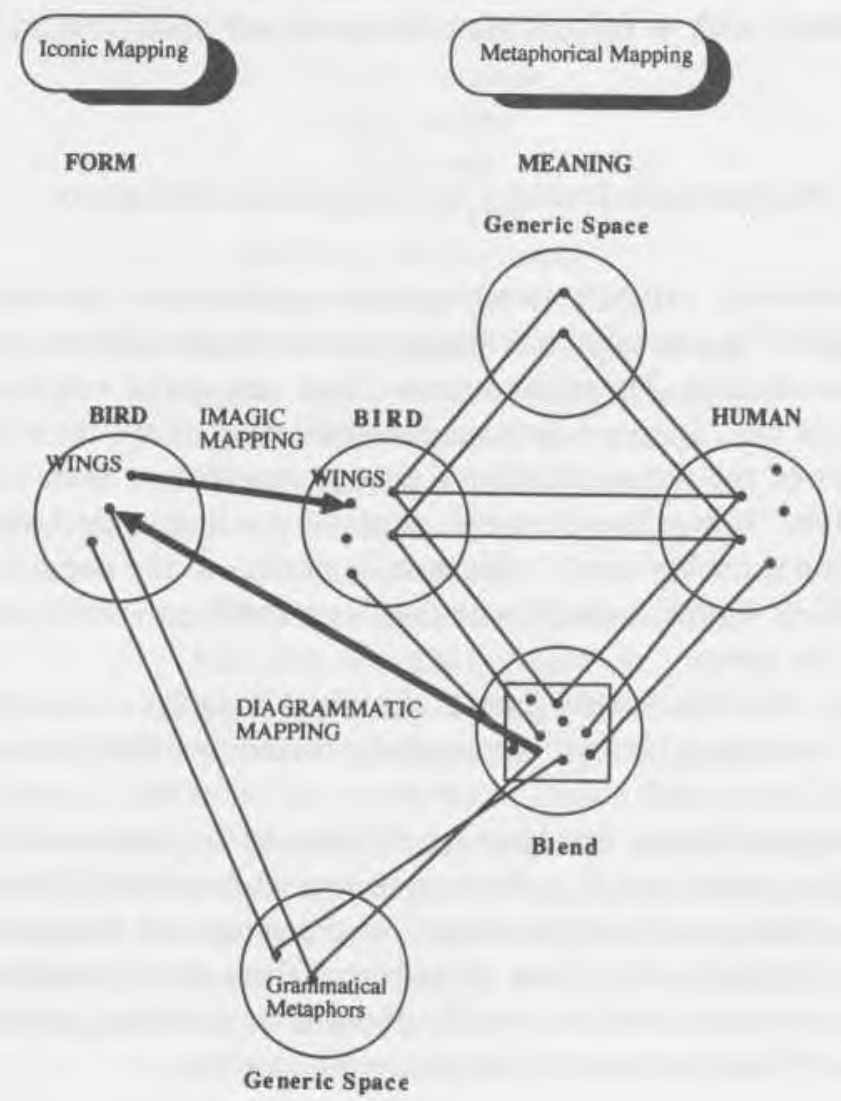

Figure 5. Metaphor-Icon Link in "Easter Wings"

This metaphorical reading leads on to suggest a diagrammatic iconic mapping between the form (the space on the left-hand side) and the blended space, as indicated by the arrow in Figure 5.

Notice that the wings, an icon for the bird, had to be put vertically on the pages in order to display the fact that they are wings and the bird is rising. The wing shape is an imagic icon because it is a direct mimicry. The rising shape, on the other hand, is a result of the reading of the poem's content. The wings on the 
second page look smaller because the first and the last lines are shorter than those on the previous page. They give the impression that the bird on the second page has taken off or is flying further.

Seen as a global metaphor, the vertical form of the two wings is charged by layers of religious readings provided by Christian tradition and culture. The form embodies the metaphorical meaning of Easter as celebrating Christ's being born again, or rising from death, awakens associations with spiendidly winged angels, and image patterns such as fall and rise, decay and advance, loss and victory, to list but a few.

\section{Diagrammatic Iconicity by Grammatical Metaphors}

The poem, moreover, exhibits structural correspondences between form and meaning navigated by conventional metaphors for linguistic forms as discussed in the previous section. The most narrow lines are given emphasis both by location, i. e., at the centre of each stanza and length, i. e., their brevity. The central position of the wings displays a phrase repeated in both verses of the poem, 'With thee.' If one interprets this poem as a religious declaration against a Christian cultural background, 'with thee' is central to the poem's declaration of belief. The focal significance of 'with thee' is centralised visually or physically in the core of the poem.

In addition, 'with thee' at the joint of the wings suggests a relationship - as if that most poor creature at his most diminished is saved by a hand reached out. The other short lines, one in each stanza, 'most poor' and 'most thin', form a pair. There is an analogical link between the shortness of form and the smallness of the objects ('man' in the first stanza, and $\mathrm{T}$ in the second stanza) described ${ }^{15}$. The third line in the first stanza, 'Decaying more and more', also corresponds diagrammatically to the decrease in the length of the lines of the poem. These correspondences are more subtle and less noticeable than the overall silhouette of the poem; nonetheless, they are as important. These are cases of diagrammatic iconicity.

\section{Imagic Iconicity by Visual Layout}

It is clear that the imagic iconicity dominates in this text because, if we put the words of the poem in an ordinary prosaic format or even in a horizontal layout

15 There are other repetitions in the poem. For example, *... became most...', 'let me ...', *... this day thy victories', and 'the flight in me' are repeated in each stanza. These repetitions reinforce the content expressed. 
as in Example 2, the intended iconic effect of the poem is easily lost (Harris 1995: 61) ${ }^{16}$.

Example 2

Lord, who createdst man in wealth and store,

Though foolishly he lost the same,

Decaying more and more,

Till he became

Most poore:

With thee

$\mathrm{O}$ let me rise

As larks, harmoniously,

And sing this day thy victories:

Then shall the fall further the flight in me.

My tender age in sorrow did beginne:

And still with sicknesses and shame

Thou didst so punish sinne,

That I became

Most thinne.

With thee Let me combine

And feel this day thy victorie:

For, if I imp my wing on thine,

Affliction shall advance the flight in me.

In short, the meaning expressed by the language and the visual form of this poem constitute simultaneously an image, a diagram and a metaphor of "Easter Wings". The image is the dominant iconic manifestation in this particular example; but, the creativity of this image is enhanced by the diagrammatic and metaphorical manifestations as clariiled by the analysis.

${ }^{16}$ Surprisingly, the poem appears in horizontal form in many modem editions (see Herbert 1994[1633]: 35 , for example). 


\title{
4.2. Grammatical Parallelism in Shelley's "Love's Philosophy"
}

\author{
Text as Metaphor
}

Love's Philosophy ${ }^{17}$

The fountains mingle with the river, $\quad 1$

And the rivers with the ocean, 2

The winds of heaven mix for ever 3

With a sweet emotion; 4

Nothing in the world is single, $\quad 5$

All things by a law divine 6

In one another's being mingle- $\quad 7$

Why not I with thine? $\quad 8$

See the mountains kiss high heaven, $\quad 9$

And the waves clasp one another; $\quad 10$

No sister flower would be forgiven 11

If it disdained its brother: $\quad 12$

And the sunlight clasps the earth, 13

And the moonbeams kiss the sea- $\quad 14$

What are all these kissings worth, $\quad 15$

If thou kiss not me? 16

P. B. Shelley's "Love's Philosophy" (1904 [1820]: 216) abounds in the use of local metaphors ${ }^{18}$. Let us see what conventional metaphors are employed in the text and how they are sculpted into the composite metaphorical conception for the given target space, which is hinted at by the title of the poem, "Love's

17 There is a different version of the poem in The Poetical Works of P. B. Shelley, published by Oxford University Press, 1943. The basic claims made in this paper also applies to this version.

18 The choice of this particular poetic text is my own; but, the choice of the English Romantic period was suggested by Donald Freeman (1978a). He says, "The poets of the English Romantic period were concerned perhaps more than those of any other epoch with the role of poetic language in a theory of poetry. The Romantic era thus is a highly appropriate locus for an inquiry into the relationship between poetic syntax and poetic structure. That relationship is one of iconicity: syntactic patterns in these poems correlate in particularly rich and interesting ways with the statement that each poem makes" (1978a: 654655). For an analysis of iconicity in English Romantic poems, see also Freeman ( 1978b), Ross (to appear). 
Philosophy." The abundant use of metaphorical expressions reflects conventional cognitive metaphors as follows:
a. A NATURAL PHENOMENON IS AN ENTITY
b. A NATURAL OBJECT IS AN ENTITY
c. FEELING IS AN ENTITY
d. NATURE IS HUMAN
e. OPPOSITES FORM PAIRS
f. FUSION IS MIXING
g. UNDERSTANDING IS SEEING
h. CONTACT IS TOUCHING
i. REQUESTING IS QUESTIONING
j. LOVE IS A FUSION OF OPPOSITES
k. LOVE IS CONTACT
1. LOVE IS PAIRING

The first cognitive metaphors, A NATURAL PHENOMENON IS AN ENTITY, A NATURAL OBJECT IS AN ENTITY and FEELING IS AN ENTITY, are what Lakoff and Johnson ( 1980: 25-32) call 'ontological metaphors' which enable us to conceive continuous events, on-going realities, and unstable or even moving states of things as if they were quantifiable objects, entities or units with which we can refer to, quantify, identify and so on. In this poem, NATURAL PHENOMENA and NATURAL OBJECTS such as 'fountains', 'rivers', 'winds', 'mountains', 'heaven', 'waves', 'sunlight', 'earth', 'moonbeams' and 'sea' are treated as discrete ENTITIES which have boundaries and shapes. 'Emotion' is seen as if it were an ENTITY, which is countable and even modifiable by an adjective of taste, 'sweet'.

Furthermore, some of these entities are personified by the NATURE IS HUMAN metaphor: e.g., the 'mountains' that 'kiss' high 'heaven', the 'waves' that 'clasp' one another, the 'sister flower' that 'disdained' its 'brother flower', the 'sunlight' that clasps the 'earth', the 'moonbeams' that 'kiss' the 'sea.' It might be worth pointing out in this connection that some of the metaphors are what Lakoff and Turner (1989) classified as a nonconventional expansion of conventional metaphors. For example, the metaphor of a 'sister-flower' disdaining its 'brother-flower' in the lines 11 and 12 extends the NATURE IS HUMAN metaphor to include not only the male/female distinction but also the particular kinship of brother and sister.

The ENTITIES are put into semantic oppositions such as: LARGE vs. SMALL ('river' vs. 'fountain'; 'ocean' vs. 'river'); HUMAN vs. DIVINE ('emotion' vs. 'heaven'); HUMAN vs. NATURE ('emotion', T, 'thou', 'me', 'thine', 'brother', 'sister' vs. 'fountains' 'river' 'ocean', 'wind', 'mountains', 
'waves', 'flower', the 'sunlight', 'earth', 'moonbeams', 'sea'); EARTH vs. HEAVEN ('fountains', 'river', 'ocean', 'mountains', 'waves', 'flower', 'earth', 'sea' vs. 'heaven', 'law', 'divine', 'sunlight', 'moonbeams'); MAN vs. WOMAN ('brother' vs. 'sister'; T vs. 'thou'; 'me' vs. 'thine'); WATER vs. SOIL ('fountains', 'river', 'ocean', 'waves', 'sea' vs. 'earth', 'mountains'); and DAY vs. NIGHT ('sunlight' vs. 'moonbeams').

FUSION is expressed by the verbs of MIXING such as 'mingle' and 'mix.' What is FUSED has the same quality: SHAPELESSNESS. The image of FUSION is thus introduced by the MIXTURE OF THE FLOW OF LIQUID, such as the 'fountains' mixed with the 'rivers', and the 'rivers' with the 'ocean', and by the MIXTURE OF THE FLOW OF THE INVISIBLE, such as the 'winds' mixed with each other with a 'sweet emotion.'

As the poem progresses, the image of FUSION turns into the image of CONTACT, particularly PHYSICAL CONTACT. It seems to indicate the progression of the lover's longing from an abstract fantasy to a concrete vision. The opening line of the second stanza starts with the verb 'see', in the imperative mood. This is a focal point. The act of seeing merges with its double meaning via the metaphor UNDERSTANDING IS SEEING, and the seeing by the physical eye and the mind's eye fuse. The cognitive metaphor UNDERSTANDING IS SEEING is pervasive in ordinary language. For example, "I see what you mean", "It looks different from my point of view", "I was totally in the dark during the presentation she gave", "I've got the whole picture", and "He gave an illuminating paper."

CONTACT is expressed by the verbs of PHYSICAL BINDING and TOUCHING such as 'clasp' and 'kiss.' Those being united by PHYSICAL CONTACT are PERSONS, i.e., PERSONIFIED NATURAL OBJECTS. Obviously the poem uses nonconventional elaboration of image-schemas such as "the mountains kiss the heaven", "the sunlight clasps the earth", "the moonbeam kisses the sea". In the conventional metaphors, PERSONIFIED NATURE may 'touch' and 'manipulate' objects such as "the mountain ridge touched the sky", or "wind carries seeds"; but, it does not interact to as fully human an extent as described by this poem.

PAIRING is implied by the semantic oppositions as pointed out above; but, it is expressed in more specific terms by a paired set of antonyms such as $\mathrm{T}$ and 'thou', 'brother' and 'sister', 'sun' and 'moon.' The image of PAIRING is also supported by the abundance of MIXING and CONTACT metaphors.

Each stanza ends with a question, which also implies a double meaning: an inquiry and a request. While the questions at the end of the poem are direct questions, they also function as a request, longing and/or wooing (indirect speech acts). Thus, each stanza is a REQUEST (LONGING, WOOING) in the form of a QUESTION. 


\section{Global Metaphor}

Now that it is clear that many of the metaphorical expressions in this poem are based on conventional cognitive metaphors that we use in everyday language, then, the question is how Shelley exploited conventional metaphors to create his unique poetic text. We have pointed out that he used a nonconventional extension and elaboration of conventional metaphors to some extent. Nevertheless, the most prominent technique is the formation of composite metaphors by combining multiple conventional metaphors together to produce a richer and more complex set of metaphorical networks, which gives inferences beyond those that follow from each of the metaphors alone.

The overall global mapping present in the poem is a mapping of the NATURE domain onto the HUMAN domain. All the MIXING and FUSION and CONTACT in NATURE are mapped onto the PAIRING of two lovers. The network of composite metaphors discussed above constitutes a series of local blends, which are recruited at the time of the global blend of NATURE and HUMAN. The input source space has a rich imageschematic structure provided by various pairing acts of natural phenomena and objects. The input target space recruits an image-schematic structure from our common-sense knowledge and background information about the lovers.

The image-schematic structure of each input space is preserved in the abstract structure in the generic space, a frame of PAIRING, in this example. A frame of PAIRING is schematised in two ways: a coupling of the two things, similar (e.g., the water and the water, the waves and the waves, the flower and the flower, the human and the human) and different (e.g., the solid and the air, brother and sister, man and woman).

In the blended space, all these structures from the generic space and the input spaces are preserved, and in addition, some emergent structures arise. For example, the separation of the two lovers. The lovers in this poem have not been united. Shelley's poem is a blend which recruits inferences not only from linguistic conventions instantiated in a composite metaphorical network but also from common-sense knowledge, culture, tradition, history and religion. The poem can be a general statement about love's philosophy. It can also address the potentiality of what may happen. Or it can also be Shelley's own message to his lover. The poetic imagination extends the conventional metaphors of love to the realm both of the poet's particular experience and of potential experience of all lovers, which all reside in the blend. 


\section{Iconic Interpretation by Metaphor}

Figure 6 illustrates the metaphorical blend discussed above and the diagrammatic iconic mappings to be explained in detail below. The point in this particular poetic text is that the poem's form can acquire an iconic meaning by the grammatical metaphors which actually constitute the content of the two generic spaces (Generic Space 2 and 3) for the two iconic mappings.

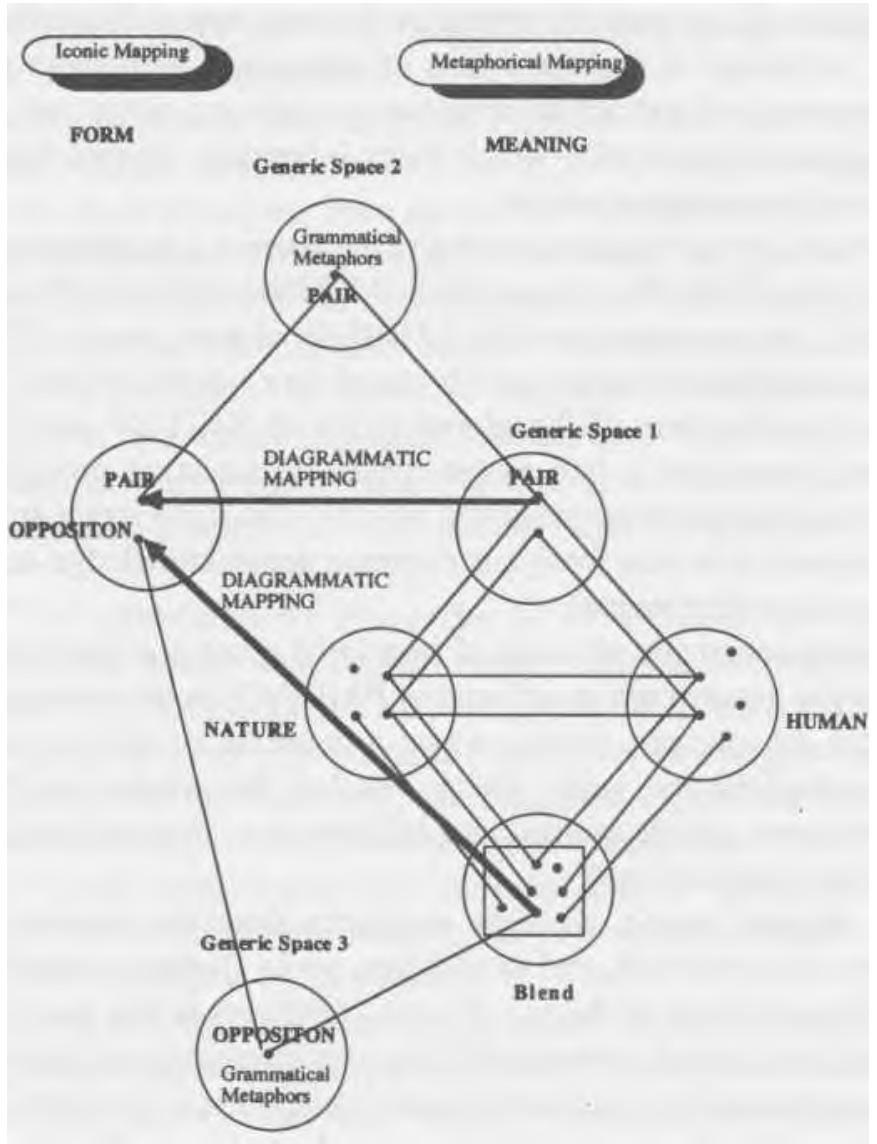

Figure 6. Metaphor-Icon Link in "Love's Philosophy"

Firstly, there is a diagrammatic mapping between the schematic structural form of the poem and the image-schema of the generic space (Generic Space 1. a frame pairing the similar and the different) of global metaphor, bridged by the 
generic space of a grammatical metaphor (Generic Space 2, A PAIRED FORM IS A PAIRED CONTENT). Secondly, there is another diagrammatic mapping between the schematic structural form of the poem and the image-schema of the blended space. This concerns an iconic mapping of the image-schema of separation projected through the generic space (Generic Space 3, AN OPPOSING FORM IS AN OPPOSING CONTENT).

\section{A PAIRED FORM IS A PAIRED CONTENT}

Let us now look at the lexical architecture of the poem. The frequency of the use of certain words in this poem mirrors PAIRING, which is a shared image- schematic frame of the global metaphor. Even a hasty reader would notice that several lexical items are used repeatedly. The most prominent characteristic of these repetitions is that the same (or similar) items are repeated only twice as if they are PAIRING each other. There are ten identical pairs and five semi-identical pairs, which are either derivationally or inflectionally similar. Table 2 shows these pairs and their position in the text.

Table 2: Lexical Pairs in "Love's Philosophy"

\begin{tabular}{|l|l|l|}
\hline \multicolumn{1}{|c|}{ Parts of speech } & \multicolumn{1}{|c|}{ Lexical item } & Line number \\
\hline Verb & $\begin{array}{l}\text { mingle } \\
\text { clasp }\end{array}$ & $\begin{array}{l}1 \text { and } 7 \\
10 \text { and } 13\end{array}$ \\
\hline Noun & river & 1 and 2 \\
& heaven & 3 and 9 \\
\hline Pronoun & one another & 7 and 10 \\
& $1-$ methine - thou & 8 and 16 \\
& it - its & 8 and 16 \\
& & 12 and 12 \\
\hline Determiner & all & 6 and 15 \\
& a & 5 and 6 \\
& no - nothing & 8 and 11 \\
& why - what & 8 and 16 \\
\hline Adverb & not & 5 and 7 \\
\hline Preposition & in & 12 and 16 \\
\hline Coniunction & if & \\
\hline
\end{tabular}


On the stanzaic level, too, the first and the second stanza form a PAIR in such a way that each stanza has the same number of elements lexically, syntactically and prosodically, as summarised in Table 3.

Table 3: Stanzaic Pairs in "Love's Philosophy"

\begin{tabular}{|l|l|l|}
\hline & \multicolumn{1}{|c|}{ First stanza } & \multicolumn{1}{c|}{ Second stanza } \\
\hline $\begin{array}{l}\text { Lexical items } \\
\text { Repeatedly } \\
\text { used }\end{array}$ & six the's & six the's \\
\hline two be's & four with's & two be's \\
\hline Adjectives & $\begin{array}{l}\text { four kiss's } \\
\text { sweet }\end{array}$ & one adjective-high \\
\hline Plural nouns & $\begin{array}{l}\text { four nouns - } \\
\text { fountains, rivers. } \\
\text { winds, and things }\end{array}$ & $\begin{array}{l}\text { four nouns - } \\
\text { mountains, waves. } \\
\text { moonbeams, and } \\
\text { kissings }\end{array}$ \\
\hline Introductory sentence & affirmative & affrmative \\
\hline Concluding sentence & interrogative & interrogative \\
\hline Rhyme scheme & ababcdcd & ababcdcd \\
\hline
\end{tabular}

Lexically, the first and the second stanza have the following: six the's, two be's (including 'being'), one lexical item repeated four times (i.e., four with's in the first stanza and four kiss's in the second), one adjective (i.e., sweet in the first stanza and high in the second), four plural nouns (i.e., fountains, rivers, winds, and things in the first stanza and mountains, waves, moonbeams, and kissings in the second).

Syntactically, there are five affinmative sentences and one interrogative sentence in each stanza. And prosodically, both stanzas have the same end rhyme scheme, i.e., ababcded.

\section{AN OPPOSING FORM IS AN OPPOSING CONTENT}

The fact that the poem consists of two stanzas indicates that the stanzaic form of the poem itself is a means of the OPPOSING PAIRS making CONTACT. This also holds true in the alternation of indentation of the even lines, with further alternation of paired line initials (And-With-All-Why in the first stanza, and And-If-And-If in the second stanza). 
The syntactic features of some elements and the syntactic patterns in the text also reflect the image-schemas of OPPOSITES. Firstly, the OPPOSITION of $\mathrm{T}$ and 'thou' seems to be supported by the presupposed SEPARATION between $\mathrm{T}$ and 'thou', expressed by the final questions of each stanza, which contain a negation: "why not I with thine?" and "what are all these kissings worth, if thou kiss not me?" (Italics mine.) Secondly, the OPPOSITIONS are also embodied in the grammatical differences between the first and the second stanza as shown in Table 4:

Table 4. Syntactic Oppositions in "Love's Philosophy"

\begin{tabular}{|l|l|l|}
\hline & \multicolumn{1}{|c|}{ First stanza } & \multicolumn{1}{c|}{ Second stanza } \\
\hline Verbs & all intransitive & all transitive \\
\hline No. of prepositions & one & none \\
\hline
\end{tabular}

In the first stanza, the verbs are all intransitive, and each line has one preposition, whereas in the second stanza, the verbs are all transitive, and there is no preposition. Hence, the first stanza and the second stanza are grammatically contrastive. In addition, the affirmative introductory sentences and the interrogative concluding sentence form an OPPOSITION within each stanza, though they form a PAIR between the first and the second stanza.

\section{Multi-Layered Metaphor-Icon Link}

We have seen so far how this poem manifests a multi-layered metaphor-icon link. There are several conventional conceptual metaphors sculpted into the composite metaphorical conception of LOVE. There are images in local metaphors, too, which enrich the feel of the poem by mapping a mixing act of waters, and of invisible air onto a mingling act of lovers, by mapping a contact of visible natural objects and of fragrant flowers onto the kissing of lovers. The lexical, syntactic and stanzaic form of the poem displays a diagrammatic relationship to the content of the text navigated by the global metaphorical blend as well as conventional grammatical metaphors.

To summarise, "Love's Philosophy", describing the longing of a narrator to be one with his separated (or unreachable) lover, displays the theme iconically and metaphorically in its cognitive content, linguistic form and image, particularly achieved by a creative choice of vocabulary and grammatical patterns. Indeed, the poem is a metaphorical icon of 'love's philosophy.' The analysis by the model of blending has demonstrated how and where the organic unity of the 
poem is buttressed by diagrammatic and metaphorical coherence between the formal dimension and the dimension of concept and image in the poetic text.

\section{Concluding Remarks}

This study has shown that the model of blending offers a useful analytical tool to explain the mechanism of iconic and metaphorical mapping in cognitive terms. An original contribution of this paper is the demonstration of the effectiveness of this model for clarifying the complex interrelationship between metaphor and iconicity in the dynamic production of meaning in language in general, and in poetic texts in particular.

It has been demonstrated that a close metaphor-icon link is manifest in two ways: (1) that there are iconic (both imagic and diagrammatic) moments in metaphor; and (2) that a form acquires an iconic meaning by grammatical metaphors. The analysis of the link in ordinary language and poetic texts has illustrated that the model of blending can specify which parts of the metaphorical process - whether the input, generic or blended spaces relate to the diagrammatic iconic mapping of form and meaning.

Poems can be varied in their metaphor-icon structure. "The Easter Wings" is dominantly iconic and has a much less rich use of metaphor, while "Love's Philosophy" is particularly rich and complex in its metaphor with respect to cognitive, image and grammatical aspects. These two poems are believed to be at relatively extreme ends of the spectrum and, to some extent, can be used as measuring standards for other poems to be analysed in future studies. Some poems show the metaphor-icon link in the visual and syntactic modalities as illustrated in the examples in the present paper. Others display such a link in auditory modality. The poetic analysis of this paper has proved that the metaphoricon link is not a simple one. We need a detailed reading of the texts in their various aspects - visual and auditory forms, structure of meaning, pragmatic and cultural contexts and background information in order to see how the interplay of metaphor and iconicity contributes to the creation and interpretation of meaning.

What remains for future investigation is a qualitative sophistication of the analysis for the purpose of concise and precise explanation, and quantitative evidential support from different types of material resource such as visual, auditory and formal modalities of language structure and use, in different languages and different genres (cf. D. Freeman 1993, Hiraga 1997, 1998, M. Freeman, in press, among others). 


\section{References}

Anderson, D. 1984. "Peirce on Metaphor". Transactions of the Charles S. Peirce Society: A Quarterly Journal in American Philosophy 20(4), 453-468.

Bennett, J. 1963. Five Metaphysical Poets. 3'd Edition. Cambridge: Cambridge University Press.

Bolinger, D. 1977. Meaning and Form. London: Longman.

Danesi, M. 1995. "The Iconicity of Metaphor". In Syntactic Iconicity and Linguistic Freezes:

The Human Dimension, ed. Marge E. Landesberg, 265-284. Berlin: Mouton de Gruyter.

Freeman, D. C. 1978a. "Syntax and Romantic Poetics". In Proceedings of the 12th

International Congress of Linguists, eds. Wolfgang U. Dressier and Wolfgang Meid, 654-

657. Innsbruck: Innsbrucker Beitrage zur Sprachwissenschaft.

Freeman, D. C. 1978b. Keat's 'To Autumn': Poetry as Process ad Pattern. Language and Style 11, 3-17.

Freeman, D. C. 1993. 'According to My Bond': King Lear and Re-Cognition. Language and Literature 2(1), 1-18.

Freeman, M. In press. "Poetry and the Scope of Metaphor: Toward a Cognitive Theory of Literature." In Metaphor and Metonymy at the Crossroads, ed. Antonio Barcelona. Berlin: Mouton de Gruyter.

Haiman, J. 1985a. Natural Syntax: Iconicity and Erosion. New York: Cambridge University Press.

Haiman, J.. Ed. 1985b. Iconicity in Syntax. Amsterdam: John Benjamins.

Halliday, M. A. K. 1994. "The Construction of Knowledge and Value in the Grammar of Scientific Discourse, with reference to Charles Darwin's The Origin of Species." In Advances in Written Text Analysis, ed., Malcolm Coulthard. London: Routledge.

Harris, R. 1995. The Signs of Writing. London: Routledge.

Herbert, G. 1880 [1633]. "Easter Wings." The Temple. Cambridge: T. Buck and R. Daniel, Printers to the University of Cambridge.

Haiman, J. 1994[ 1633]. "Easter Wings." The Works of George Herbert, 35. Ware, Hertfordshire: Wordsworth Editions.

Higgins, D. 1977. George Herbert's Pattern Poems in Their Tradition. Unpublished Editions. West Glover, Vermont and New York.

Hiraga, M. K. 1994. "Diagrams and Metaphors: Iconic Aspects in Language." Journal of Pragmatics 22(1), 5-21.

Hiraga, M. K. In press, 1999a. “"Blending' and an Interpretation of Haiku: A Cognitive Approach.” Poetics Today.

Hiraga, M. K. In press, 1999b. "Rough Sea and the Milky Way: 'Blending' in a Haiku Text." In Computation for Metaphors, Analogy and Agents, ed. Chrystopher Nehaniv, Berlin: Springer-Verlag.

Hkobson, R. 1971 (1966) J. "Quest for the Essence of Language." In Selected Writings 11, 345-359. The Hague: Mouton. 
Jakobson, R. and L. R. Waugh. 1979. The Sound Shape of Language. Bloomington, IN: Indiana University Press.

Johnson, M. 1987. The Body in the Mind: The Bodily Basis of Meaning, Imagination, and Reason. Chicago: University of Chicago Press.

Lakoff, G. 1987. Woman, Fire, and Dangerous Things: What Categories Reveal about the Mind. Chicago: Chicago University Press.

Lakoff, G. 1993. "The Contemporary Theory of Metaphor." In Metaphor and Thought, ed. Andrew Ortony, 202-251. 2nd ed. Cambridge: Cambridge University Press. Lakoff, G. and M. Johnson. 1980. Metaphors We Live By. Chicago: Chicago University Press.

Lakoff, G. and M. Turner. 1989. More than Cool Reason: A Field Guide to Poetic Metaphor. Chicago: Chicago University Press.

Peirce, Ch. S. 1955(1902]. "Logic and Semiotic: Theory of Signs." Philosophical Writings, ed. Buehler, Justus, 98-119. New York: Dover.

Reddy, Michael. 1970. "The Conduit Metaphor." In Metaphor and Thought, ed. Andrew Ortony. Cambridge University Press.

Ross, J. R. To appear. "The Taoing of a Sound: Phonetic Drama in William Blake's The Tyger." In Phonosymbolism and Poetic Language, ed. Patrizia Violi. Turnhout, Belgium: Brepols.

Shelley, P. B. 1904(1820]. "Love's philosophy." In The Golden Treasury, ed. Francis T. Palgrave. London: MacMillan.

Summers, J. 1954. George Herbert: His Religion and Art. London: Chatto and Windus. Taub, S. 1997. Language in the Body. Unpublished doctoral dissertation. University of

California, Berkeley.

Turner, M. 1996. The Literary Mind. Oxford: Oxford University Press.

Turner, M. 1998. "Figure.” In Figurative Language and Thought, eds. Albert N. Katz. Cristina Cacciari, Raymond W. Gibbs, Jr. and Mark Turner, 44-87. Oxford: Oxford University Press.

Turner, M, and Gilles Fauconnier. 1995. 'Conceptual Integration and Formal Expression.' Metaphor and Symbolic Activity 10(3), 183-204.

Turner, M. In Press, 1999. "A Mechanism of Creativity." Poetics Today.

Tuve, R. 1952. A Reading of George Herbert. Chicago: University of Chicago Press. Walker, J. D. 1962. "The Architectonics of George Herbert's The Temple." English Literar History 29, 289-306.

Waugh, L. R. 1992. "Presidential Address: Let's t Take the Con out of the Iconici: Constraints on Iconicity in the Lexicon." American Journal of Semiotics 9, 7-48.

Waugh, L. R. 1994. "Degrees of Iconicity in the Lexicon." Journal of Pragmatics 22( 1 u 55 70.

Westerweel, B. 1984. Patterns and Patterning: A Study of Four Poems by George Herbc L Amsterdam: Rodopi. 